\title{
TRENDS IN DAIRY SECTOR IN BALTIC COUNTRIES
}

\author{
Aleksandra Rizojeva-Silava, Sandija Zeverte-Rivza \\ Latvia University of Life Sciences and Technologies, Latvia \\ aleksandra.rizojeva@gmail.com, sandija.rivza@1lu.lv
}

\begin{abstract}
Agriculture is an important sector of the economy in the European Union (EU) and milk production is one of the most significant agricultural sectors in Latvia, Estonia and Lithuania (Baltic countries). It has proven itself as the sector with stable development and future perspective and these countries are substantial producers of milk and milk products. During the last years farms involved in commercial milk production often had substantial modernization, the farmers are motivated to improve animal welfare, feeding and also genetics and hygiene standards, which leads to higher productivity and milk quality, thus providing economic gains to farmers. The purpose of this study is to analyse the dairy sector in the Baltic countries and trends in its historical development. To reach these purposes research tasks were set, which helped analyse the key elements of the dairy sector in the Baltic countries. After joining the EU, the dairy sector in all Baltic countries has changed small dairy farms could not complete the new technological requirements and hygiene standards of milk production and left the business, thus reducing the amount of dairy cows countrywide, however, farmers generally choose cows with higher genetic potential that can produce more milk in lactation and improve the feeding and welfare conditions that lead to higher productivity. The sector is also heavily influenced by milk price changes in the key markets in the EU and the EU support. However, the dairy sector in Latvia, Estonia and Lithuania is still the most important agricultural commodity production sector besides grain production.
\end{abstract}

Keywords: dairy, purchase price, trends.

\section{Introduction}

Milk production is one of the significant agricultural sectors in all Baltic countries and it has proven itself as the sector with stable development and future perspective. Agricultural production is unusual compared with most business activities in its strong dependence on biological processes [1]. The Baltic countries are substantial producers of milk and milk products. During the last 14 years farms involved in commercial milk production often had substantial modernization, the farmers are motivated to improve animal welfare, feeding $[2 ; 3]$ and also genetics and hygiene standards, which lead to higher productivity and milk quality, thus providing economic gains to farmers.

Milk production takes place in all EU countries and represents a significant proportion of the value of the EU agricultural output [3]. Although altogether over the last more than ten years after accession to the EU the dairy sector has gone through modernization and intensification, it has also foreseen several rapid price drops causing financial crises to milk producers, unfavorable market changes and also the Russian embargo for import of milk products. All these changes have created a sense of instability of the sector and forced several of the dairy farmers out of the business or change their specialization to livestock farming [4]. Especially those farmers with high financial liabilities taken to modernize their farming are severely affected and vulnerable to rapid milk price changes compared to small and medium size dairy farmers, who are usually more financially independent and resilient. The EU uses a number of mechanisms to protect the milk sector during times of increased market disturbance [3; 4].

\section{Results and discussion}

In the structure of agriculture production in the Baltic countries, milk production is the most important sector among animal farming sectors. Improvement of genetic quality of cows and herd management have resulted in annual increase in the average milk yield per lactation, thus the total milk yield is also increasing [3].

As the Baltic countries are members of the EU, all of its decisions also affect these countries. For example, a strong impact on the milk sector in the Baltic counties had milk quotas, which were introduced by the EU on the $1^{\text {st }}$ of April, 2010. After five years of a preparatory increase in their level, milk quotas were abolished on the $1^{\text {st }}$ of April, 2015, which led to the increase of milk production all over the EU between 2015 and 2016[5]. Also, Russian embargo on import of products (including dairy products) had a major impact on the dairy sector in all EU countries, including the Baltic countries [6]. 
The next event that will definitely affect the dairy sector across Europe is Brexit, it is not yet known how much will be affected.

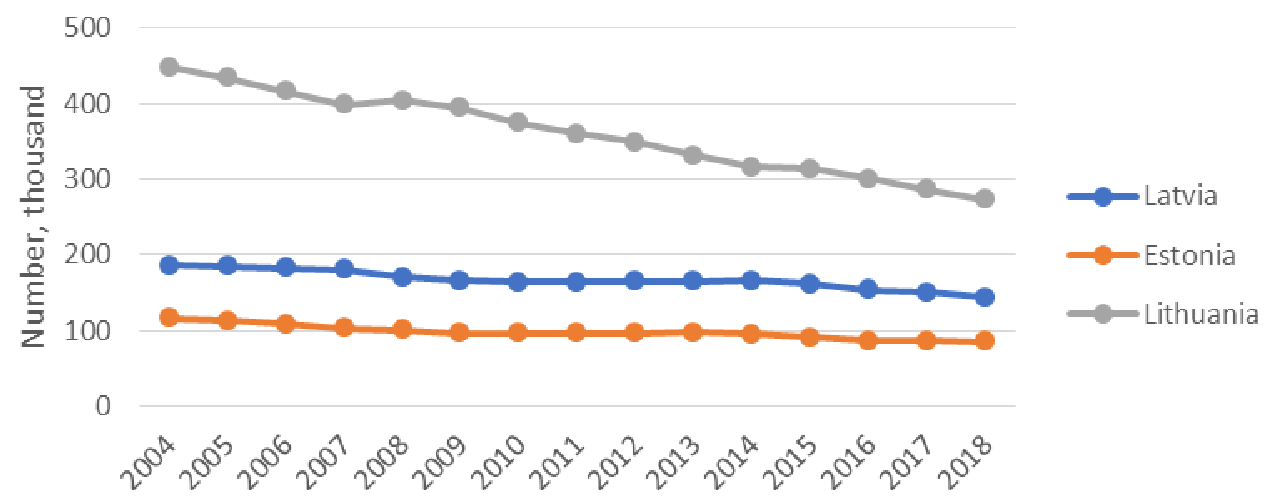

Fig. 1. Number of dairy cows

The number of dairy cows in the Baltic countries has decreased from 2004 till 2008. Fig.1 shows that the difference is that in Estonia and Latvia the decrease was small each year, whereas in Lithuania the decrease was significant, from 448 thousand in 2004 to 273 thousand in 2018. Comparison of 3 countries shows that Estonia had the lowest number of dairy cows from the beginning, only 117 thousand in 2004, meanwhile in Latvia in that year there were 186 thousand dairy cows in 2004 and in Lithuania 448 thousand in 2004 [7-9].

Fig. 2 shows that despite the fact that the number of dairy cows has decreased, milk production (including milk yield per cow) in the Baltic countries continues to increase. Average milk yield per cow over 14 years in Latvia increased from $4251 \mathrm{~kg}$ in 2004 to $6614 \mathrm{~kg}$ in 2018 (which is $55.59 \%$ ); in Estonia from $5528 \mathrm{~kg}$ in 2004 to 9287 in 2018 (which is $68 \%$ ); in Lithuania from $5068 \mathrm{~kg}$ in 2004 to $8524 \mathrm{~kg}$ in $2018(68.19 \%)$ [7-9].

It means that farmers generally choose cows with higher genetic potential that can produce more milk in lactation and improve the feeding and welfare conditions that lead to higher productivity.

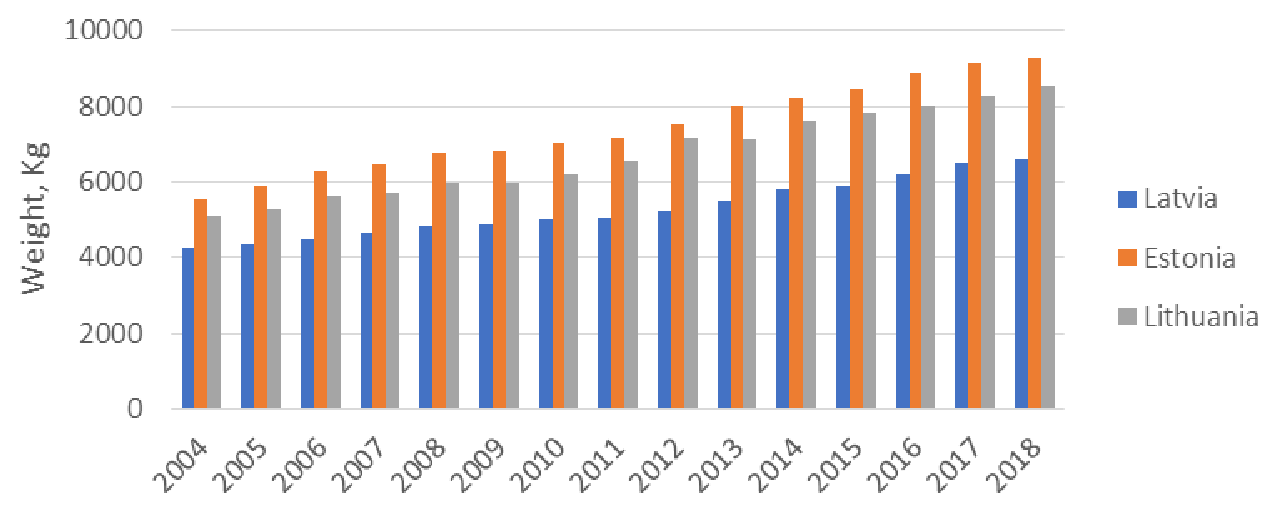

Fig. 2. Average milk yield per cow

Average milk yield is depending on breed specialization and the technical level of the farms and dairy industry [10]. The increase in productivity is also linked to the farm structure - as more and more small scale farmers with less productive cow herds and smaller milk yields are leaving the business, medium and large dairy farms with better and more precisely managed livestock farming and thus higher milk yields increase the overall productivity. And it indicates that the transition to precise agriculture, which is the basis of successful modern agriculture, is also a significant aspect in dairy farming. Comparison of Lithuanian, Latvian and Estonian dairy farms revealed that Lithuanian farmers performed relatively well, but Estonian farmers showed the highest growth rates $[11 ; 12]$. The Estonian government supplied lower extra financial support for farmers during the dairy crisis, as a result, Estonia went through a dramatic increase in the farm size over the last years and average milk yield per cow [7]. 


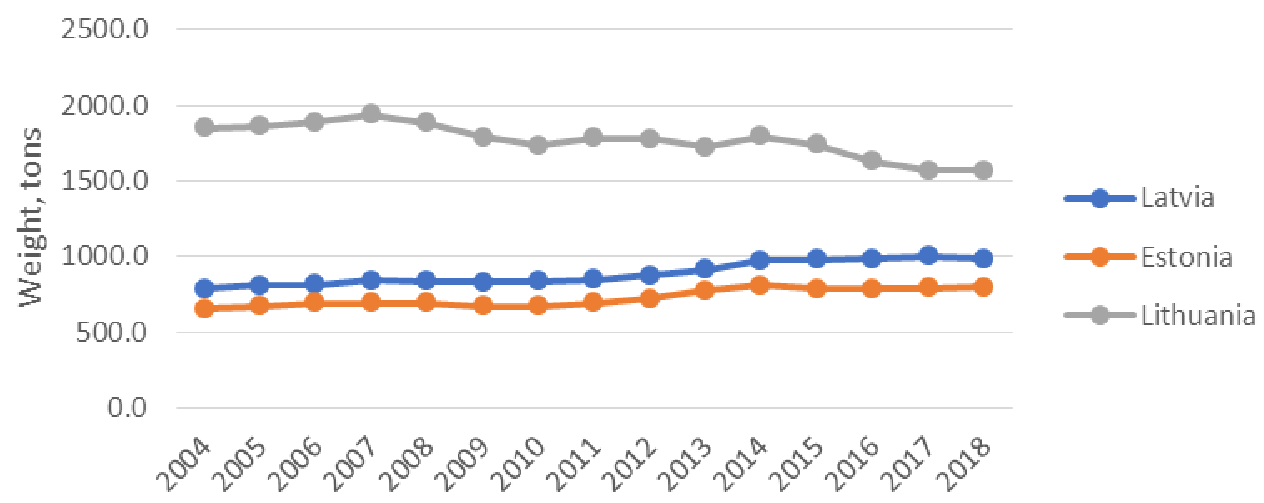

Fig.3. Raw milk production

Fig. 3 shows that raw milk production during the last 14 years in the Baltic countries varied. For example, in Latvia and Estonia raw milk production has been relatively stable, with reductions or increases in some years, but in Lithuania, raw milk production was unstable. Figure 3 shows that milk production in Estonia and Latvia started to increase in recent years: in Latvia from 2009 to 2017 and also in Estonia from 2009 to 2018, while in Lithuania from 2014 it started to decrease. One of the reasons why raw milk production in Lithuania is decreasing rather than growing is that Lithuania buys more raw milk from other countries (for example, from Latvia). Fig. 6 shows another reason and it is the low milk purchase prices [7-9].

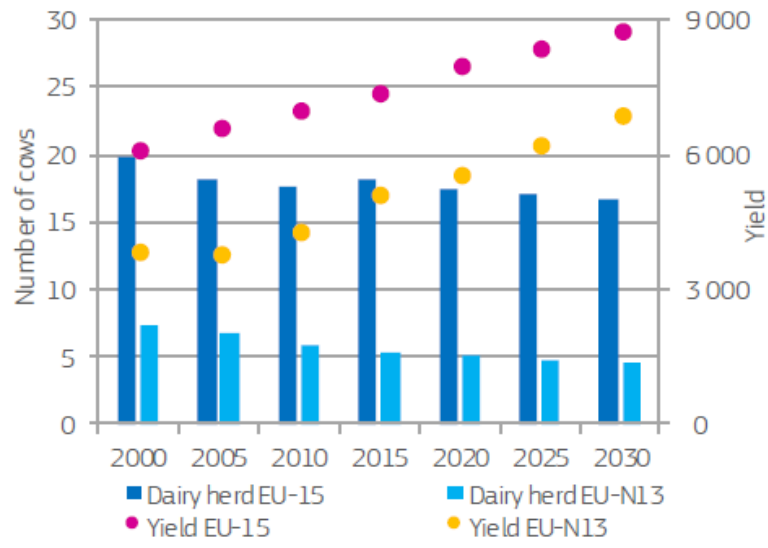

Fig.4. Number of cows (million heads) and yield (kg/cow) in the EU [14]

By 2030, average yields are expected to grow. The projected yield annual growth is however slower than in 2008-2019 due to the increasing diversity of production systems. Thanks to these efficiency gains, the number of dairy cows could be reduced by 1.4 million, to 21.2 million heads ( $6 \%$ below the 2019 level) [14].

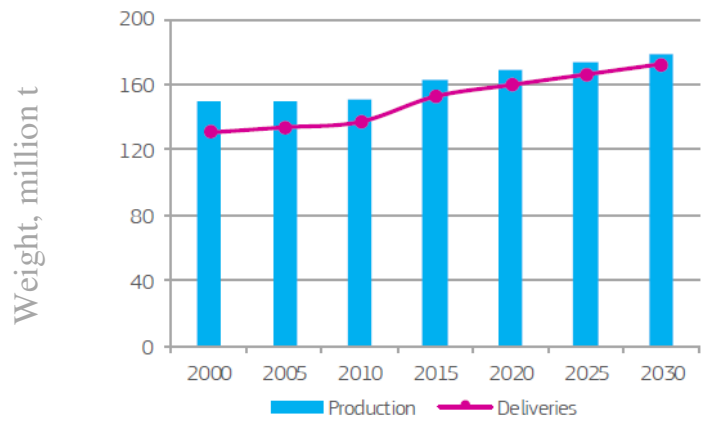

Fig. 5. EU milk production and deliveries (million t) [14] 
At the same time, increasing yields could lead to a reduction in GHG emitted per kg of milk. It means that the EU milk production is expected to continue growing to 179 million $\mathrm{t}$ by 2030 , but at a slower pace $(+0.6 \%)$ than in $2008-2019(+1 \%$ per year on average) [14].

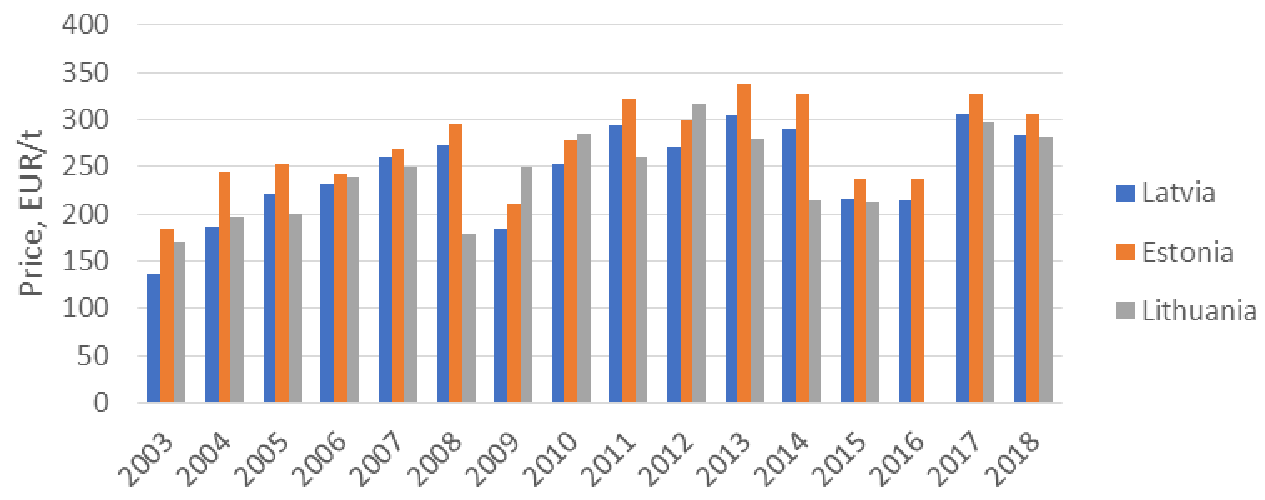

Fig. 6. Purchase prices for milk

Milk production is a sector characterized by rapid changes in prices and "crisis" stages, when the milk purchase price drops below the milk cost. Especially negatively these fluctuations affect the group of small farmers, whose milk purchase price is about $10 \%$ lower than for other farms. The milk purchase price in the Baltic countries is closely related to the price of milk in the world and in the EU; therefore, global changes affect the local milk price and cause fast fluctuations in milk prices [2;6].

Milk purchase prices in Latvia were stable, mostly rising, slight declines were in 2009, 2012 and in the period 2014-2016. In Estonia, milk purchase prices were the highest compared to Latvia and Lithuania. Milk purchase price declines, just like in Latvia, were in 2009 and 2012, as well as in 2014 and up to 2018.In Lithuania the situation is slightly different from Latvia and Estonia. There the milk purchase price decline was observed 1 year before it took place in Latvia and Estonia, namely in 2008, 2011 and 2013. Like in Latvia, there has been a rise in milk purchase prices in recent years. The main reasons for the decline in the milk purchase price in the Baltic countries were the import ban imposed by the Russian Federation (embargo) as of 7 August 2014 and the incoming volatility of the global dairy market, and the sharp decline in the demand in Asia, especially in China [5; 6]. Another reason for milk production increasing is that the demand cannot keep up and as a result milk purchase prices are falling.

As the Baltic countries are part of the EU, the changes in the milk purchase price in the Baltic countries are to a big extent dictated by the milk price in the EU and the key markets of the EU.

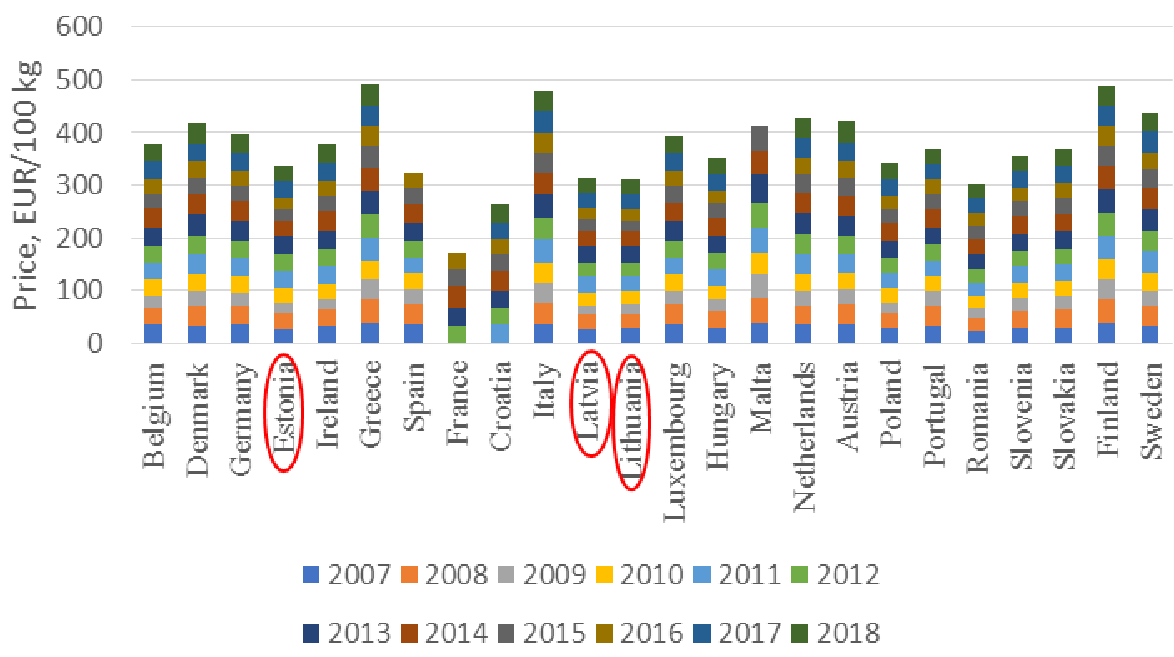

Fig. 7. EU selling prices of raw cow's milk 
Fig.7 shows that selling prices of raw milk in the Baltic countries are by far the lowest in comparison with other EU countries. In the last 11 years, the highest prices were observed in Greece. The main reasons of the high prices in Greece are the high price of raw inputs, high cost of collection and distribution. The Russian embargo also affected other EU countries, not only the Baltic countries $[16 ; 17]$.

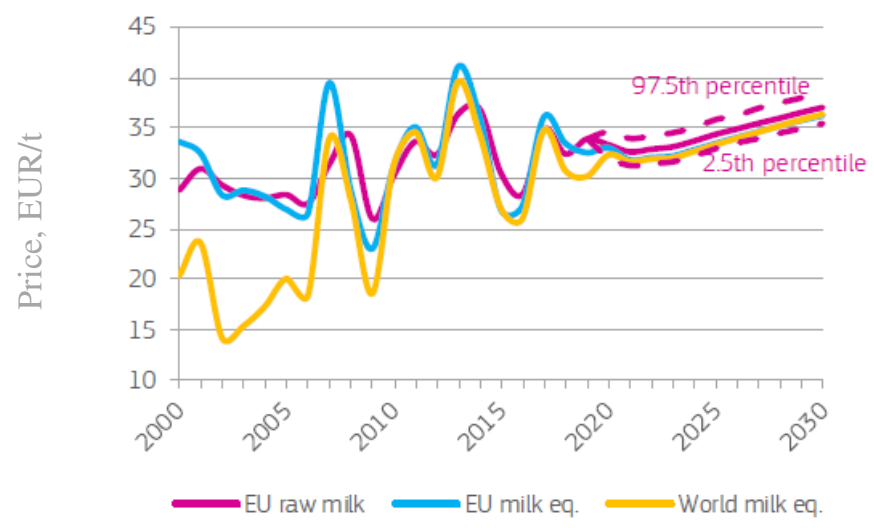

Fig. 8. EU milk price $\left(E U R \cdot t^{-1}\right)$ and uncertainty range [14]

Fig. 8 shows that milk prices are forecasted to increase in the EU and globally. It allows assuming that the milk price in the Baltic countries will continue to increase over the coming years, following the increase of the milk price in the EU [14].

\section{Conclusions}

1. The number of dairy cows in the Baltic counties has decreased in the time period 2004-2008, but milk production continues to increase. It means that farmers generally choose cows with higher genetic potential that can produce more milk in lactation and improve the feeding and welfare conditions that lead to higher productivity.

2. Raw milk production during the last 14 years in the Baltic countries varied. In Latvia and Estonia raw milk production has been relatively stable, with reductions or increases in some years, but in Lithuania raw milk production was unstable

3. The changes in the milk purchase price in the Baltic countries are to a big extent dictated by the milk price in the EU and the key markets of the EU.The main reasons for the decline in the milk purchase price in the Baltic countries were the import ban imposed by the Russian Federation (embargo) as of 7 August 2014 and the incoming volatility of the global dairy market and the sharp decline in the demand in Asia, especially in China. Another reason for milk production increasing is that the demand cannot keep up and as a result milk purchase prices are falling.

4. By 2030, average yields are expected to grow, the EU milk production is expected to continue growingand milk prices are forecasted to increase in the EU and globally.

\section{References}

[1] Allen P.G. Economic Forecasting in agriculture.International Journal of Forecasting. USA, 55 p.

[2] Paura L., Arhipova I. Analisys of the milk production and milk price in Latvia, Procedia Economics and Finance, vol.39, 2016, pp. 39-43.

[3] European Commission. Milk and dairy products. [online] [12.12.2019]. Available: https://ec.europa.eu/info/food-farming-fisheries/animals-and-animal-products/animalproducts/milk-and-milk-products_en.

[4] Rizojeva-Silava A., Zēverte-Rivža S., Rivža B. Trends in the Dairy Sector in Latvia. Prceedings of international conference "5th International Multidisciplinary Scientific Conference SOCIAL SCIENCES \& ARTS SGEM 2018”, August 24 - September 02, 2018, Albenia, pp.89-93.

[5] Archive: Milk and milk products - 30 years of quotas. Retrieved: https://ec.europa.eu/eurostat/statistics explained/index.php/Archive:Milk_and_milk_products__30_years_of_quotas\#Dairy_cows. 
[6] Chaptea A., Caigne C. Russian food embargo and the lost trade. Retrieved March 4, 2019, from: https://ageconsearch.umn.edu/record/276238/files/wp18-05.pdf.

[7] Central Statistical Bureau of Latvia. Latvia. Main statistics indicators. [online] [22.02.2020]. Available at: https://www.csb.gov.lv/sites/default/files/publication/2018-

05/Nr\%2002\%20Latvija\%20Galvenie\%20statistikas\%20raditaji\%202018\%20\%2818_00\%29\%20 LV.pdf

[8] Lithuanian Official Statistic Portal. [online] [14.02.2020]. Available: https://osp.stat.gov.lt/EN/statistiniu-rodikliu-analize?hash=627e6385-1020-4bac-b10016df658328af\#/.

[9] Estonian Statistical Database. [online] [21.01.2020]. Available: http://pub.stat.ee/pxweb.2001/I_Databas/AG_Census/AGC2001/14Livestock/06General_data_of_livestock/06Genera 1_data_of_livestock.asp.

[10] Pulina G., Milán M.J. Lavín M.P. etc. Invited reviews: Current production trends, farms structure, and economics of the dairy sheep and goat sectors. Journal of Dairy Science, vol. 101, 2018, pp. 6715-6729.

[11] Latvian Rural Advisory and Training Centre. Retrieved: http://new.llkc.lv/lv/nozares/lopkopiba/govju-skaits-mazinas-izslaukums-pieaug.

[12] Stalgiene A., Jedi A., Wire AH. Market Power in Lithuanian, Latvian, and Estonian Dairy Sectors: The Case of Raw Milk Market. Transformations in Business \& Economics, Vol. 16, 2017, pp. 89-105.

[13]Dairy Global. Estonia's ambitious plans for dairy. [online] [10.03.2020]. Available: https://www.dairyglobal.net/Market-trends/Articles/2017/9/Estonias-ambitious-plans-for-dairy$190137 \mathrm{E} /$.

[14]EU Agricultural Outlook for Markets and Income 2019 -2030. [online] [ 07.03.2020]. Available: https://ec.europa.eu/info/sites/info/files/food-farming-fisheries/farming/documents/agriculturaloutlook-2019-report_en.pdf.

[15] Eurostat. Milk and milk product statistics. [online] [27.11.2019]. Available: http://ec.europa.eu/eurostat/statistics-explained/index.php/Milk_and_milk_product_statistics.

[16]EUROSTAT. Milk and milk product statistics. [online] [21.04.2020]. Available: $\mathrm{https}: / /$ ce.europa.eu/eurostat $/ \mathrm{gm} /$ download.do?tab=table \&plugin $=1 \&$ language $=$ en $\& p c o d e=t a g 000$ 70.

[17] OECD Competition Assessment Reviews: Greece. [online] [21.04.2020]. Available: https://books.google.lv/books?id=ACXjAwAAQBAJ\&printsec=frontcover\&hl=ru\#v=onepage \&q $\& \mathrm{f}=$ false 